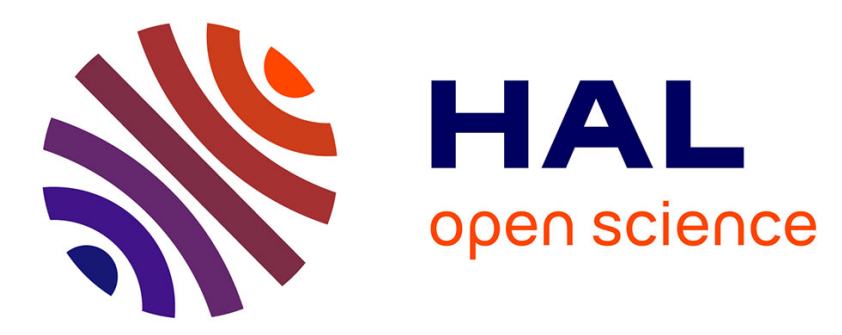

\title{
Antimicrobial effect of medical textiles containing bioactive fibres
}

A. Mariscal, R. M. Lopez-Gigosos, M. Carnero-Varo, J. Fernandez-Crehuet

\section{To cite this version:}

A. Mariscal, R. M. Lopez-Gigosos, M. Carnero-Varo, J. Fernandez-Crehuet. Antimicrobial effect of medical textiles containing bioactive fibres. European Journal of Clinical Microbiology and Infectious Diseases, 2010, 30 (2), pp.227-232. 10.1007/s10096-010-1073-1 . hal-00632886

\section{HAL Id: hal-00632886 https://hal.science/hal-00632886}

Submitted on 17 Oct 2011

HAL is a multi-disciplinary open access archive for the deposit and dissemination of scientific research documents, whether they are published or not. The documents may come from teaching and research institutions in France or abroad, or from public or private research centers.
L'archive ouverte pluridisciplinaire HAL, est destinée au dépôt et à la diffusion de documents scientifiques de niveau recherche, publiés ou non, émanant des établissements d'enseignement et de recherche français ou étrangers, des laboratoires publics ou privés. 


\section{Title page}

$\underline{\text { Title }}$

\section{Antimicrobial effect of medical textiles containing bioactive fibres}

Authors

Alberto Mariscal ${ }^{1 *}$

Rosa M. Lopez-Gigosos ${ }^{1}$

Manuel Carnero-Varo ${ }^{2}$

Joaquin Fernandez-Crehuet ${ }^{2}$

${ }^{1}$ Department of Preventive Medicine, Faculty of Medicine, Malaga University

${ }^{2}$ Service of Preventive Medicine, Hospital Clinic of Malaga

Running title: Antimicrobial textiles

${ }^{*}$ Corresponding author:

Department of Preventive Medicine, Faculty of Medicine, Malaga University

Boulevard Louis Pasteur, 32

29071 Malaga, Spain

Tel.: +34 952131515; Fax: +34 952137131; mariscal@uma.es 


\section{Antimicrobial effect of medical textiles containing bioactive fibres}

\section{Summary}

Over the last few years, the textile industry has developed different methods for obtaining fabrics and fibres with an antimicrobial action for use in hospital environments and for other purposes. This study evaluates the antimicrobial action of Bioactive ${ }^{\circledR}$ treated fabric (BTF), a commercially available textile containing silver for use in healthcare environments. Unlike other biocides used in hospital fabrics, the prolonged use of silver has not been related to the appearance of resistant bacteria or crossresistance to antibiotics, in spite of being extensively used in some treatments. Thirtythree hospital strains of bacteria were tested. This study showed the capacity of BTF for significantly reducing the number of microorganisms present, compared with the reduction observed in control fabrics (CF). The antimicrobial action of BTF was expressed as $\log _{10}$ reduction (LR) from an initial inoculum of about $10^{5}$ colony-forming units. According to the bacterial species, a LR of between 2.6 and 5.0, and 4.1 and 5.0 (5.0 indicating total inhibition of bacterial growth) were observed respectively after 24 and 48 hours for BTF. Acinetobacter strains were the most resistant to CF after 72 hours (0.8 LR). All the microorganisms, except two strains of Enterococcus faecalis, were totally inhibited after 72 hours on BTF.

Keywords: biocide, fabric, textiles, in vitro efficacy 


\section{Introduction}

The majority of microorganisms that are most frequently identified as the cause of nosocomial infections are ubiquitous gram-negative or gram-positive bacteria, which can be isolated on a large variety of inert surfaces found in hospitals and human skin, including the hands of medical staff. Although the role of environmental contamination in nosocomial cross-transmission leading to infections remains unresolved [1], routine cleaning and disinfection is an habitually recommended practice in hospital environments [1-3].

Recently, it has been suggested that hospital textiles and other contaminated plastic materials could be a source of nosocomial infections, contributing to the transmission of pathogens both through indirect contact, via hospital staff, endogenously, and by means of aerosols [4,5]. The characteristics of the textile in question, together with humidity and heat, can create the right conditions for the proliferation of numerous microorganisms $[6,7]$. The prevalence of microorganisms in the hospital setting could be reduced by using effective antibacterial compounds adhering to frequent contact surfaces, such as curtains, uniforms or sheets, as well as other materials. Although their efficacy has not yet been shown in clinical tests, some of these materials are commercially available and used in a large number of hospitals $[5,6]$. In any case, as indicated by a number of authors, common sense suggests that the reduction of the bacterial load on common contact surfaces should lessen the probability of a specific infectious dose of bacteria being transmitted by health workers to susceptible patients [7]. 
The purpose of this study was to examine the survival of several clinical bacterial isolates on an antimicrobial fabric containing silver, and to evaluate their in vitro efficacy and potential usefulness in clinical trials.

\section{Material and methods}

Bacterial strains

A collection of microorganisms isolated in different pathological samples, representing the clonal complexity associated with nosocomial infections at the University Hospital of Malaga, were studied (see table 1). Three clinical strains of Pseudomonas aeruginosa, with an exceedingly high mucosity, were also included, although they were considered separately from other non-mucous strains. Four reference microorganisms were also employed: Escherichia coli ATCC25922, Pseudomonas aeruginosa ATCC27853, Morganella morganii ATCC 25830, and Staphylococcus aureus CIP53154. All cultures of gram-negative bacteria were maintained on tryptic soy agar (TSA; Panreac) slants and sub-cultured monthly. Columbia agar with sheep's blood (CA; Oxoid) was used for gram-positive bacteria.

\section{Bacterial suspension}

Each strain was cultured separately in $25 \mathrm{ml}$ of Tryptic soy broth (TSB; Panreac) at $37^{\circ} \mathrm{C}$ for 22 hours, harvested by centrifugation at $9000 \mathrm{~g}$ for 5 minutes at $4^{\circ} \mathrm{C}$, and rinsed twice with PBS buffer. The rinsed bacteria were then suspended in PBS to obtain about $10^{6} \mathrm{cfu} / \mathrm{ml}$, and the viable counts determined on TSA or CA agar plates. A $100 \mu \mathrm{l}$ aliquot containing about $10^{5} \mathrm{cfu}$ of each of the strains was used as a cell suspension. 
The test fabric (BTF) was Bioactive $®$-treated polyester/cotton (80/20) supplied by Interasa (Spain). According to the manufacturer, the presence of bioactive polyester fibers in BTF finishes is $67 \%$ (the silver ion concentration on the bioactive fibers is 180 ppm). Untreated polyester/cotton (80/20) fabric was used as a control (CF). Autoclaved $5 \mathrm{~cm}^{2}$ squares of BTF or CF were placed in Petri dishes separately and $100 \mu \mathrm{l}$ of a cell suspension were smoothly deposited on their surface. Petri dished were maintained at a room temperature of $25^{\circ} \mathrm{C}$ and between $40-60 \%$ of humidity for $3,24,48$, or 72 hours. Fabrics were then removed using sterile forceps and introduced separately in a sterile test tube containing $10 \mathrm{ml}$ of $0.2 \%$ Tween-80 in PBS buffer (PBS-Tween). The tubes were then shaken for 30 minutes at room temperature in an orbital shaker.

Two 48-well plates (six rows and eight columns) with a lid (Iwaki brand, Asahi Techno Glass, Japan), each containing 100 (Column 1) or $900 \mu \mathrm{l}$ (Columns 2-8) of freshly prepared TSB-RS - TSB diluted 1:10 in PBS buffer containing 1:125 $(\mathrm{v} / \mathrm{v})$ resazurin solution, obtained from Sigma, Cat. No. R-6892 - were used in each test, one for BTF and the other for CF.

Aliquots $(0.9 \mathrm{ml})$ of the test tubes were then plated in the six wells of the first column of the 48-well plate, prepared as described above. Thereafter, decimal dilutions were performed to column 7 using a multichannel pipette, new pipettes being used for each dilution. The last columns were used as controls without bacteria. The plates were prepared in triplicate, and incubated for $20 \mathrm{~h}$ at $37^{\circ} \mathrm{C}$ in the dark. The colour change was then assessed visually, and any all changes - from purple to pink or colourless were recorded as positive [8]. The higher dilution at which colour change occurred (HD) was taken to estimate the bacterial concentration. Simultaneously, after extracting 
aliquots, the fabrics were then removed and blotted onto TSA or CA plates during another 30 minutes. The fabrics were then removed and the plates incubated overnight at $37^{\circ} \mathrm{C}$.

A measure of the antimicrobial efficacy of BTF - expressed as $\log _{10}$ reduction (LR) was calculated from the mean HD for BTF subtracted from the mean HD for CF (Eq. 1).

$$
L R=\bar{x} H D_{C F}-\bar{x} H D_{B T F}
$$

Depending on the inoculum size ( $\log _{10}$-transformed and rounded off to 5$)$ and the dilution procedure, a viable cell density of between $\approx 10^{4}$ and $\approx 10^{\circ} \mathrm{cfu} /$ well was expected for Columns 1-5; the cell density for HD being predictably between 1 and $10^{1} \mathrm{cfu} /$ well (the last dilution in which a color change can be produced). In this way, if an observable change in colour appeared only in Column 1, HD was noted as 1 (between 1 and 10 cfu: $\log _{10}$-transformed and rounded off to 1 ); if the observable change in colour appeared in Columns 1 and 2, HD was expressed as $2\left(2 \log _{10}\right)$, and so on and so forth for the rest of the columns. When no column in BTF exhibited a change of color $\left(H D_{B T F}=0\right)$, then $L R$ was equal to $H D_{C F}$, showing that the bacterial growth had been completely inhibited by BTF. In each test, six strains of the same, or different, species were assayed on the same plate, and the test was repeated for each strain on three different days. The standard deviation of these replicas (repeatability SD) was then calculated. Dunnett's one-sided many-to-one test was performed to compare the HD of BTF and CF for each strain.

\section{Results}


In the first part of this study, the capacity of resazurin for detecting small inoculums, in the 1-10 cfu range under the aforementioned test conditions, for each one of the test strains, was established according to previous studies [9]. Although a change in colour was observed in the first dilutions after 2-3 hours of incubation, 18 hours were needed for the lowest dilutions, in which the detection of only 1-10 microorganisms, depending on the count, was expected.

In each one of the assays, a count of the number of cell suspension microorganisms was simultaneously conducted as a test suitability control. The average results obtained in counts of the bacterial suspensions of the strains and replicas used in tests are shown in Table 1. Those tests with counts outside the $2-8 \times 10^{6} \mathrm{cfu} / \mathrm{ml}$ range in the cell suspension were left out of following analyses.

Table 1 shows the average bacterial inhibition (as LR) between 3 and 72 hours after the inoculums were deposited on BTF and CF. Owing to the size of the inoculum deposited on each fabric (about $10^{5} \mathrm{cfu}$ ), an LR value of 5 indicated that no microorganisms had survived after the contact period. The reference strains used in this study have also been included in the aforementioned table, since no differences were observed in the tests in relation to the clinical strains.

As can been seen in Table 1, the highly mucous $P$. aeruginosa strains were those that showed a lower capacity of survival after 3 hours on BTF. After 24 hours, however, all those inoculums deposited on BTF showed a higher LR in relation to CF. Only two strains of $E$. faecalis survived after 72 hours of contact. 
Likewise, the survival of inoculated microorganisms on CF was in all cases greater than that obtained on BTF, except when there was complete inhibition in both cases $(L R=5)$. The microorganisms with the greater capacity for survival after 72 hours of contact with CF belonged to the Acinetobacter strains.

In short, Figure 1 shows as a percentage of inhibition, the average LR values obtained in each period for all of the analyzed microorganisms on BTF and CF. As can be seen, the greatest differences in survival occurred after 24 hours of contact. Jointly, the bacterial inhibition rate after 72 hours of contact with CF $(77.3 \%)$ was similar to that of microorganisms after 24 hours of contact with BTF (78.7\%). Nevertheless, practically all the microorganism deposited on BTF $(99.64 \%)$ failed to survive after 72 hours of contact.

\section{Discussion}

Over the last decades, many strategies have been developed in order to reduce nosocomial infection rates $[6,10]$. Nevertheless, although a better knowledge and implementation of infection control practices has had some impact on the prevalence of nosocomial infections [7], infection rates remain high and additional strategies are continuously required. So as to try to reduce these infection rates, some efforts have been geared to developing fabrics containing antibacterial components for use on surfaces in frequent contact with patients, such as uniforms, bedding, curtains, and upholstery $[5,7,11]$. 
The aim of this study was to examine the antimicrobial efficacy of a commercially available biocide textile on some of the microorganisms that are most frequently responsible for nosocomial infections.

A number of methods have been developed to determine the efficacy of antimicrobial textiles [12]. Among all the developed methods, the suspension test is the only one that allows us to obtain quantitative values, but it is very time-consuming and requires a lot of material. In these tests, a bacterial inoculum is usually deposited on the test fabric and allowed to dry at room temperature. Afterwards, the absorbed bacteria are eluted and a plate count is carried out.

In the test conducted in this study, the use of microtiters allowed us to reduce the amount of manipulation required; the antimicrobial effect is easily visible in the microtiter's wells thanks to the incorporation of resazurin as a growth indicator; and readings can also be automated by using a conventional microtiters reader. The resazurin assay's applicability for quantifying the cell density on the well microtiters was estimated from the HD values for each inoculum and the corresponding cfu/well estimated by plate count. A good repeatability was confirmed by the variation coefficient obtained in HD quantification (CV 2-9\%) from the replicates. In addition, the test fabric is finally blotted onto agar plates, making it possible to determine the presence of noneluted microorganisms adhered to the fabric. In some tests, for instance, bacterial growth was not observed for some of the strains in any of the microtiter plate wells: however, some isolated colonies (no more than six or ten) were indeed observed in the agar plates on which the respective fabrics had been deposited (in such cases, LR was given as 4). Under the test conditions of this study, none of the strains showed a high 
level of adherence to BTF or CF. In the aforementioned tests, isolated colonies only grew on the agar plates, on which the corresponding fabrics had been deposited, in some of the replicas with strains of $P$. aeruginosa and S. epidermidis. Likewise, with the exception of these assays, a visible colour change in the microtiter plate was matched by a confluent, or partially confluent, growth on the corresponding agar plates, depending on the dilution. What is more, in the tests in which no colour change was observed on the microtiter plate $(\mathrm{LR}=5)$, the subculture of the well microtiter on TSB and the blotting of the cloth onto the agar plate resulted in no growth.

Likewise, preliminary experiments were carried out in which BTF inoculated with cell suspension was introduced, as previously described, in test tubes in which PBS was substituted by DifcoTM D/E neutralizing broth (Difco Lab, France), a commercial neutralizer containing sodium thiosulfate and sodium thioglycolate customarily used as silver neutralizers. After 30 minutes in contact with the neutralizer, there were no statistically significant differences as regards the use of the solution containing PBS, for which reason the neutralizer was not included in the method finally used. These results may indicate that the silver ions were not released from BTF fibres, at least not in a sufficiently high concentration so as to inhibit bacterial growth under the test conditions. In addition, this would be in line with the product's instructions as to silver ions bonded to a ceramic carrier are integrated into the fibres, take effect on their surfaces and remain permanently in the fabric. When using this method with other fabrics, however, the use of a neutralizing buffer in the culture medium should be analyzed.

The survival rate of a particular bacterial species on textiles or other materials can vary from one day to several weeks or from several weeks to over three months $[4,13]$. 
Besides the characteristics of each species, temperature and humidity, survival is related to the size of the inoculum and the type of material. Nonetheless, the methodology used in these studies does not allow us to determine the survival kinetics of the microorganisms on different materials. Survival is measured at regular intervals, depending on the presence or absence of viable microorganisms. So, in theory, the sole presence of one bacterium after 90 days would indicate a high survival rate for the strain in question, even though $99.999 \%$ of the inoculum had not survived more than one or two days. The length of survival of these organisms on textiles may have significant implications for infection control, but the size of the surviving inoculum with respect to its infection capacity is also important.

In this study, the method used made it possible to estimate the survival kinetics of the microorganisms on the fabrics. Although the test time range was between 3-72 hours, with 24 hour intervals, wider ranges could also be studied. As regards CF, the strains of mucous $P$. aeruginosa were the least resistant after 24 hours under test conditions, as can be seen in Table 1. These highly mucous strains were isolated in patients with cystic fibrosis, whose characteristics - difficult to cultivate and rarely recovered from the inanimate environment - are well-known and have been previously described in the literature $[14,17]$. These mucous strains were included in this study as a separate group from the non-mucous $P$. aeruginosa strains, owing to the fact that they proved to be a lot more susceptible to the study's environmental conditions, as can be observed in Table 1. The low survival rate of these mucous strains both on BTF and CF observed in this study could be related basically to the environmental conditions, in accordance with the previous studies mentioned above. 
Likewise, $A$. baumannii was the most resistant microorganism to the test conditions. $A$. baumannii is a microorganism with a very high desiccation tolerance, as has been shown in previous studies, and with an average survival rate of 27 days on glass coverslips [16]. As with the majority of those tested in this study, this microorganism did not, however, survive on BTF for longer than 72 hours.

After three hours of contact, the effect of BTF on the survival of inoculums was only observed in a statistically significant way $(p<0.05)$ on five of the ten tested bacterial species. Nonetheless, after 72 hours, only two strains of $E$. faecalis survived on BTF: the bacterial growth of the rest of the strains, including Acinetobacter, being completely inhibited.

In addition to other environmental factors, the survival rate of microorganisms on surfaces has been related to inoculum size, and different studies suggest that counts of between $10^{2}-10^{6} \mathrm{cfu} / \mathrm{cm}^{2}$ could serve as a reference value $[4,13,17]$. In this study, a $10^{5} \mathrm{cfu}$ inoculum was used and 72 hours of contact with BTF were sufficient to observe an antimicrobial efficacy of nearly $100 \%$. According to the observed survival kinetics of the microorganisms on BTF and CF, it is to be expected that large inoculums may have a greater survival rate. This, together with the effect that biological samples, like, for example, blood, can have on the survival rate of bacteria on these textiles, should be analyzed in future studies. Independently, our results suggest that the described method can be used as a simple and accurate procedure for enumerating fabricassociated bacteria and to assess the efficacy of biocidal fabric.

Although there are many references to the part played by contaminated sheets, uniforms, upholstery and other equipment as potential vehicles for transmitting 
pathogens in hospital guidelines and scientific papers, only a few epidemiological studies have been able to identify the relationship between contaminated textiles and nosocomial infections in the healthcare environment. No study to date has, however, been able to show that any textile, even uniforms, are responsible for transferring pathogens to patients in a clinical setting [18]. The capacity of adherence of a microorganism to a specific textile or any other material, together with its survival capacity depending on the environmental conditions in which the microbe is liberated, make it difficult to understand more deeply the contribution of contaminated inert materials to microorganism transmission. Recently, a pilot study with 30 patients showed a statistically significant lower colonization rate in patients sleeping in beds using biocidal sheets, compared with those that slept on regular sheets [19]. The longterm benefits associated with the use of antimicrobial textiles to prevent nosocomial infections can only be deduced by means of controlled clinical studies in real time in the hospital environment.

\section{Acknowledgments}

This work was supported by the Consejería de Educación of the Junta de Andalucía and the Ministerio de Ciencia y Tecnología in the Programa General del Conocimiento. The authors wish to thank T. MacFarlane for his helpful suggestions while translating the manuscript.

\section{References}


Table 1: Average inhibition ${ }^{1}$ of clinical and reference strains of 10 bacterial species on bioactive and control fabrics depending on the contact time.

\begin{tabular}{|c|c|c|c|c|c|c|c|c|c|c|}
\hline & \multirow{3}{*}{$\begin{array}{c}\text { № } \\
\text { strain } \\
\text { S }\end{array}$} & \multirow{3}{*}{$\begin{array}{c}\mathrm{CS} \\
\mathrm{cfu} / \mathrm{ml}\end{array}$} & \multicolumn{2}{|c|}{$3 \mathrm{~h}$} & \multicolumn{2}{|c|}{$24 h$} & \multicolumn{2}{|c|}{$48 \mathrm{~h}$} & \multicolumn{2}{|c|}{$72 \mathrm{~h}$} \\
\hline & & & $\mathrm{C}$ & $\mathrm{BT}$ & C & B T & C & B T & C & BT \\
\hline & & & $\mathrm{F}$ & $\mathrm{F}$ & $\mathrm{F}$ & $\mathrm{F}$ & $\mathrm{F}$ & $\mathrm{F}$ & $\mathrm{F}$ & $\mathrm{F}$ \\
\hline A. baumannii & 3 & $\begin{array}{l}3.5 \times 10 \\
6\end{array}$ & 0 & 0 & 0 & 2.6 & 0 & 4.1 & $\begin{array}{l}0 . \\
8\end{array}$ & 5 \\
\hline E. aerogenes & 3 & $\begin{array}{l}5.8 \times 10 \\
6\end{array}$ & 0 & 1.5 & 0 & 3.4 & $\begin{array}{l}2 . \\
2\end{array}$ & 4.3 & 4 & 5 \\
\hline E. coli & $4^{2}$ & $\begin{array}{l}5.5 \times 10 \\
6\end{array}$ & 0 & 0 & 0 & 4 & 2 & 5 & $\begin{array}{l}4 . \\
5\end{array}$ & 5 \\
\hline E. faecalis & 3 & $\begin{array}{l}3.8 \times 10 \\
6\end{array}$ & 0 & 0 & $\begin{array}{l}1 . \\
8\end{array}$ & 3.1 & 2 & 4 & 4 & 4.8 \\
\hline K. pneumoniae & 3 & $\begin{array}{l}4.0 \times 10 \\
6\end{array}$ & 0 & 0.6 & 0 & 5 & 4 & 5 & 4 & 5 \\
\hline M. morganii & $4^{2}$ & $\begin{array}{l}4.5 \times 10 \\
6\end{array}$ & 0 & 0 & 0 & 4 & 4 & 5 & 5 & 5 \\
\hline P. aeruginosa & $4^{2}$ & $\begin{array}{l}4.2 \times 10 \\
6\end{array}$ & 0 & 0.3 & 0 & 4 & 2 & 4 & 5 & 5 \\
\hline P. aeruginosa & 3 & $3.5 \times 10$ & 0 & 3.8 & 4. & 5 & 4. & 5 & 5 & 5 \\
\hline mucous & & 6 & & & 2 & & 5 & & & \\
\hline P. mirabilis & 3 & $\begin{array}{l}3.5 \times 10 \\
6\end{array}$ & 0 & 1.1 & 0 & 4 & 3 & 4.6 & 4 & 5 \\
\hline S. aureus & $4^{2}$ & $\begin{array}{l}2.8 \times 10 \\
6\end{array}$ & 0 & 1.3 & $\begin{array}{l}1 . \\
5\end{array}$ & 4.2 & 3 & 5 & 3 & 5 \\
\hline S. epidermidis & 3 & $\begin{array}{l}3.2 \times 10 \\
6\end{array}$ & 0 & 0 & $\begin{array}{l}1 . \\
6\end{array}$ & 4 & 3 & 5 & $\begin{array}{l}3 . \\
2\end{array}$ & 5 \\
\hline
\end{tabular}

\footnotetext{
${ }^{1}$ Inhibition expressed as average $\log _{10}$ reductions (LR) in relation to the inoculum size (5 $\left.\log _{10} \mathrm{cfu}\right)$

${ }^{2}$ Three clinical strains and a reference strain are included

CS, cell suspensions of inoculums as average of cfu/ml
} 
CF, control fabric

BTF, Bioactive $®$-treated fabric 
Fig. 1. Bacterial inhibition spectrum on bioactive and control fabrics

Note: Bacterial reduction was expressed as $\%$ of the average LR values obtained for the total of microorganisms in each contact time on CF and BTF

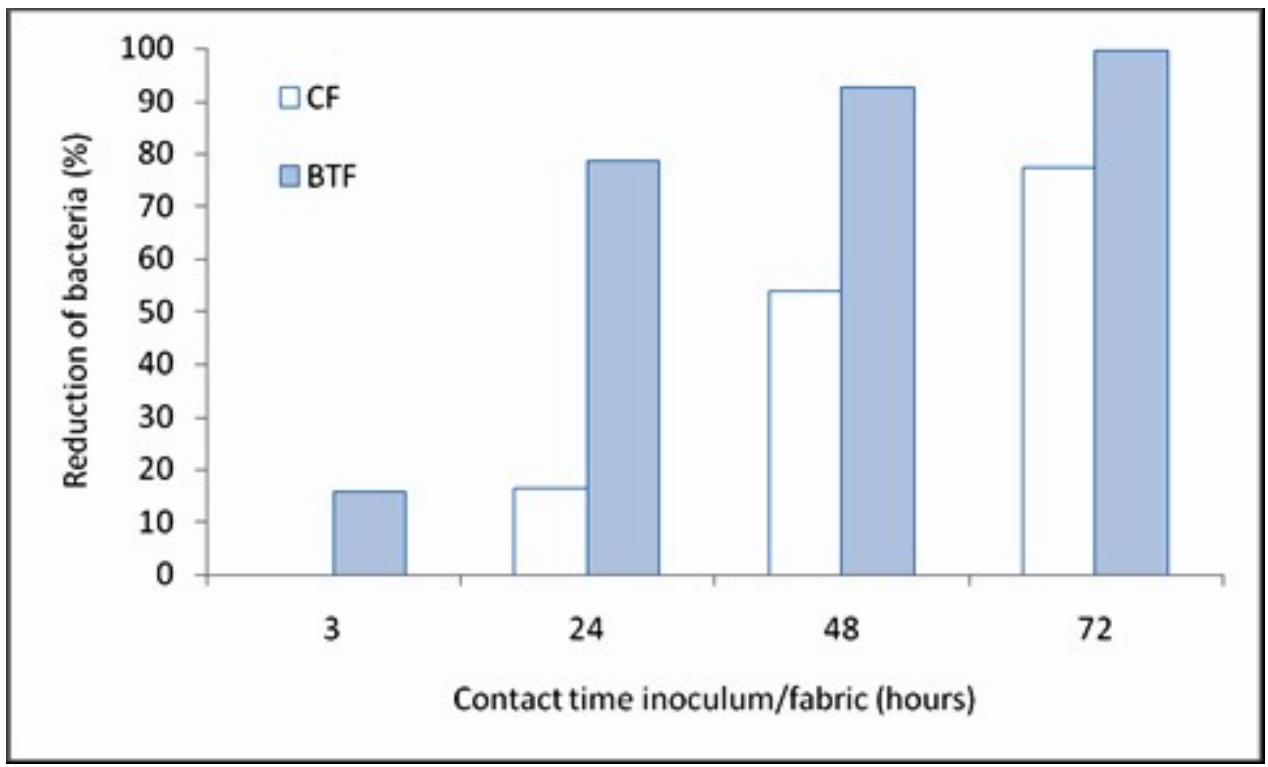

